\title{
Magnesium Sulfate as an Adjuvant in Ultrasound Guided Stellate Ganglion Block for Post Mastectomy Pain Syndrome
}

\author{
GHADA F. AL-RAHMAWY, M.D.; ENAS A. ABD AL-MOTELEB, M.D.; MONA G. EL-EBEIDY, M.D. and \\ MOHAMED A. HAFEZ, M.Sc.
}

The Department of Anesthesiology and Surgical Intensive Care, Faculty of Medicine, Mansoura University

\begin{abstract}
Background: Cancer breast is the most common cancer in women and 2 nd most common cancer overall. PostMastectomy Pain Syndrome (PMPS) is a term used to describe chronic pain following both partial mastectomy or mastectomy. It is one of many post-surgical persistent pain syndromes. Studies estimate that PMPS develops in about $25 \%$ to $60 \%$ of women leading to disability, psychological distress, and diminished quality of life.
\end{abstract}

Aim of Study: The aim of the study was to compare analgesic efficacy and duration of stellate ganglion block when using both dexamethasone and magnesium sulfate with the local anesthetic lidocaine in comparison to using dexamethasone alone with lidocaine in cases of post mastectomy pain syndrome.

Patients and Methods: Current double-blind study was conducted from September 2019 to September 2020 at outpatient pain clinic in Oncology Center Mansoura University (OCMU). Fifty female patients between age of 20 and 60 years, ASA physical status I and II underwent breast surgery. The patients were randomly assigned by computer generated sequence of random numbers method according to the drugs used into 2 equal groups, each group consisted of 25 patients, one group had received Dexamethasone and Lidocaine (group D) and the other group had received Magnesium, Dexamethasone, and Lidocaine (group DM). After block, pain score was obtained using Visual Analog Scale (VAS). The shoulder movements were measured using goniometry. The skin temperature of the ipsilateral arm to the block was also measured.

Results: After block, pain score was obtained using Visual Analog Scale (VAS). The shoulder movements were measured using goniometry. The skin temperature of the ipsilateral arm to the block was measured, the different types of shoulder movements were significantly better after injection of SGB in both groups compared to before injection. DM group showed longer analgesic duration and lower VAS score with less analgesia needed compared to D group.

Conclusion: Adding magnesium sulfate to lidocaine and dexamethasone for ultrasound guided stellate ganglion block in cases of post mastectomy pain syndrome increases the time

Correspondence to: Dr. Ghada F. Al-Rahmawy,

The Department of Anesthesiology and Surgical Intensive Care, Faculty of Medicine, Mansoura University to first request of analgesia, decreases VAS values and the total amount of analgesia needed in the follow-up.

Key Words: Post mastectomy pain syndrome - Stellate ganglion block - Visual analogue scale - Post breast surgery pain syndrome.

\section{Introduction}

CANCER breast is the most common cancer in women and 2 nd most common cancer overall. PostMastectomy Pain Syndrome (PMPS) is a term used to describe chronic pain following either partial mastectomy or mastectomy and includes women treated with sentinel lymph node dissection or complete axillary lymph node dissection. It is one of many post-surgical persistent pain syndromes. Women may describe pain in the breast, axilla, arm, or combination. This chronic condition is reported infrequently in the surgical literature and is likely under recognized by surgeons. However, the problem is not new for patients and has been recognized and described in the pain literature [1,2]

Studies estimate that PMPS develops in about $25 \%$ to $60 \%$ of women [3] . Leading to disability, psychological distress, and diminished quality of life. There is no standardized definition for PMPS it has been described as a type of neuropathic pain, a complex chronic pain state commonly associated with nerve fiber injury. Pain is typically localized to the anterior/lateral chest wall, maxilla, and/or medial upper arm and persists more than 3 months after surgery when all other causes of pain have been excluded [4]

Stellate Ganglion Block (SGB) is used in order to alleviate sympathetically maintained pain in conditions such as upper extremity complex regional pain syndrome, acute vascular insufficiency of the face and upper extremities, post-herpetic 
neuralgia, phantom pain and upper extremity hyperhidrosis [5].

This technique was first described as a blind procedure using landmarks, there are 2 main approaches for SGB: C6 transverse process approach and $\mathrm{C} 7$ anterior paratracheal approach. Now there are new techniques other than blind technique such as fluoroscopic technique, ultrasound guided technique, and CT guided technique, to decrease complications of blind technique such as vascular injury, arrhythmia, seizure and heart failure [5]

Local anesthetics are widely used in clinical practice to prevent and alleviate pain during surgery; however, their mechanisms of action are complex and incompletely understood. In addition to a prominent blocking effect on voltage-gated $\mathrm{Na}$ channels, local anesthetics also modulate many other neuronal channels [6].

Dexamethasone is a synthetic adrenocorticosteroid with potent long-acting glucocorticoid activity. Strong anti-inflammatory properties of dexamethasone have caused to introduction of "dexamethasone induced post-operative pain reduction" theory. Although analgesic mechanism of dexamethasone is still unclear, it seems that a decrease in cyclooxygenase and lipoxygenase production via inhibition of peripheral phospholipase plays a main role [7].

Locally infiltrated dexamethasone can decrease pro inflammatory factors and cytokine production in damaged tissue via lipocortin 1 (also known as annexin A1), a glucocorticoid inducible protein that has been identified as a potential endogenous mediator of the anti-inflammatory activities of glucocorticoids [8]

Although magnesium has no direct analgesic effect, it has been shown to have antinociceptive effect by blocking the N-Methyl-D-Aspartate (NMDA) receptors and associated calcium channels, thus preventing central sensitization caused by peripheral nociceptive stimulation [9] .

When mixed with local anesthetic, magnesium may also show beneficial effects in regional anesthesia. In one study, magnesium was added to lidocaine for intravenous regional anesthesia, and was found to improve quality of anesthesia and analgesia, specifically, sensory and motor block onset times were shorter and post-operative analgesia was better with magnesium [10]

This study hypothesized that adding magnesium sulfate to dexamethasone and lidocaine combination in ultrasound guided stellate ganglion block might be better than lidocaine and dexamethasone combination regarding the analgesic effect and duration of analgesia in cases of post mastectomy pain syndrome. The primary outcome was the time to first request of analgesia while the secondary outcomes were the total amount of recue analgesia needed and pain intensity on Visual Analogue Scale (VAS).

So, the aim of the study was to compare analgesic efficacy and duration of stellate ganglion block when using both dexamethasone and magnesium sulfate with the local anesthetic lidocaine in comparison to using dexamethasone alone with lidocaine in cases of post mastectomy pain syndrome.

\section{Patients and Methods}

This prospective double blind randomized controlled study was conducted from September 2019 to September 2020 at outpatient pain clinic in Oncology Center Mansoura University (OCMU). Fifty female patients between the age of 20 and 60 years old, ASA physical status I and II, underwent elective breast surgery (modified radical mastectomy) and referred to pain clinic with postmastectomy pain were included in this study. They were informed about the procedure and its possible consequences and written informed consents were obtained before the procedure.

Participants had to fulfill the following criteria: Postmastectomy neuropathic pain lasting more than 6 months after modified radical mastectomy with any of the following symptoms: Allodynia, burning pain, shooting pain, hyperalgesia, Visual Analog Scale (VAS) $\geq 4$ and limitation of the shoulder movement at the side of mastectomy.

Patients were excluded from this study if one or more of these criteria were met: Patient refusal, neuromuscular diseases as myopathies or myasthenia gravies, bleeding or coagulation disorders, any psychiatric disorders, chronic pain disease, BMI more than $35 \mathrm{~kg} / \mathrm{m}^{2}$, infection at the site of injection, participants younger than 20 years or older than 60 years, allergy to any medications used in this study.

Also, before the block all patients were evaluated regarding their systemic diseases, general condition, and coagulation status. Shoulder mobility was assessed while the patients were sitting using goniometry, the Range of Motion (ROM) was measured in degrees in different positions (flexion, extension, abduction and external rotation). Skin 
temperature was recorded in the distal portion of ipsilateral upper extremity using fever scan with values in degree Celsius. The visual analog scale was explained to the patients during assessment as 0 equal no pain and 10 equal worst pain imaginable.

Randomization: Eligible 50 patients were randomly assigned using computer generated sequence of random numbers into two equal groups (every group included 25 patients):

First group had received "Dexamethasone and Lidocaine" were termed them group (D), they had US guided stellate ganglion block using $4 \mathrm{ml}$ dexamethasone $(4 \mathrm{mg} / \mathrm{ml})+5 \mathrm{ml}$ lidoocaine $2 \%(20 \mathrm{mg} /$ $\mathrm{ml})+1 \mathrm{ml}$ saline $0.9 \%$, a total volume of $10 \mathrm{ml}$ and the second group had received "Magnesium, Dexamethasone, and Lidocaine" and we termed them group (DM), they had US guided stellate ganglion block using $4 \mathrm{ml}$ dexamethasone $(4 \mathrm{mg} / \mathrm{ml})+1 \mathrm{ml}$ magnesium sulfate $10 \%(100 \mathrm{mg})+5 \mathrm{ml}$ lidocaine $2 \%(20 \mathrm{mg} / \mathrm{ml})$, a total volume of $10 \mathrm{ml}$.

\section{Preparation of the patients:}

Before the block, an intravenous cannula was inserted and secured, all suitable resuscitation equipment and drugs were available. Vital signs, Heart Rate (HR), blood pressure and oxygen saturation $\left(\mathrm{SpO}_{2}\right)$ were monitored throughout the procedure and up to 1 hour after the block performance. Midazolam $0.02 \mu \mathrm{g} / \mathrm{kg}$ was administered intravenously as premedication if needed.

Technique of stellate ganglion block: This technique was carried out using C6 transverse process approach. The patient was lying in the supine position with the neck extended by putting a pillow under the shoulder to stretch the oesophagus away from the transverse process, and also head was slightly rotated to the side contralateral to the block and patient was asked to keep her mouth slightly opened in order to keep neck muscles relaxed. Under complete aseptic technique, a $5-10 \mathrm{MHz}$ linear probe of Siemens ultrasound was initially positioned at the level of the cricoid cartilage and the C6 transverse process was recognized by the prominent anterior tubercle (Chassaignac's tubercle). Placement of the ultrasound transducer helped to retract the carotid sheath and sternocleidomastoid to the lateral aspect. Pressure was applied with the ultrasound transducer to decrease the distance between the skin and tubercle and to depress the dome of the lung to decrease the possibility of pneumothorax. A typical sonographic appearance at the $\mathrm{C} 6$ level included the transverse process and anterior tubercle of C6, longus colli muscle (LC), longus capitis muscle, carotid artery, and thyroid gland. A 22-gauge needle was inserted and directed towards the chassaignac tubercle and after contact, it was redirected inferomedial towards the body of C6, and the needle was then withdrawn 1-2mm to bring it out of longus colli muscle while still staying within the prevertebral fascia. After negative aspiration for blood and CSF was performed, the prepared drugs $(10 \mathrm{ml})$ were injected with the ultrasound imaging which demonstrated spread of the local anesthetic agent at the area of the lower sympathetic chain. Before and after each $2 \mathrm{ml}$ bolus, the syringe was aspirated. Successful procedure was evidenced by distension of the longus colli muscle. The head of the patient's bed could be raised after injection to allow the solution to travel caudally toward the stellate ganglion to reach T4 level. The classical physical findings that appeared after a successful stellate ganglion block were the clinical manifestations of Horner's syndrome (ptosis, myosis, anhidrosis, enophthalmos) of the ipsilateral side of the block, Guttman's sign (presence of stuffing nostril), flushing of the conjunctiva and lacrimation, and increased surface temperature on the ipsilateral side of the block [11].

\section{Monitoring:}

Monitoring was carried out using a pulse oximeter for oxygen saturation, non-invasive MAP for mean ABP, five lead ECG for HR, fevers can for temperature. Baseline levels of $\mathrm{HR}, \mathrm{BP}, \mathrm{SpO}{ }^{2}$, skin temperature difference between limb on the injected side and the other side were recorded.

Also, within the first hour after injection, patients were asked about VAS score following explaining it to them as zero means no pain and 10 the worst pain and baseline VAS was recorded, after injection and at interval 2 weeks, 1, 2, and 3 months from the last injection, Gabapentin (300 $\mathrm{mg} / 8 \mathrm{hrs}$ ) was given to patients if VAS was 4 or higher. Shoulder movements (flexion, extension, abduction, internal, and external rotation) were assessed using goniometry at the same intervals of VAS score.

\begin{tabular}{|c|c|c|c|c|c|c|c|}
\hline \multicolumn{8}{|c|}{ VISUAL ANALOGUE SCALE } \\
\hline 1 & 2 & 5 & 6 & 7 & 8 & 9 & 10 \\
\hline NO PAIN & $\underset{\text { (mild) }}{\text { Annoying }}$ & $\begin{array}{r}\text { Uncom } \\
\text { (mod }\end{array}$ & $\begin{array}{l}\text { rtable } \\
\text { rate) }\end{array}$ & & $\begin{array}{l}\text { Horrible } \\
\text { (Severe) }\end{array}$ & & $\begin{array}{l}\text { W } \\
0 \\
R \\
\text { S } \\
T\end{array}$ \\
\hline
\end{tabular}

Fig. (1): visual analogue scale [12] 


\section{Collected data:}

Time to first request of analgesia, VAS after injection and at interval 2 weeks, 1,2 , and 3 months from injection, doses of gabapentin needed, number of next injections needed, skin temperature of the affected extremity, development of Horner syndrome (ptosis, miosis, anhidrosis, enophthalmos, and nasal congestion), development of complications such as hematoma, hoarseness of voice, limb weakness, pneumothorax, and hypoxia, development of hypotension which managed by administration of 5mg ephedrine if occurred after injection and the movements of the shoulder after injection.

\section{Statistical analysis and data interpretation:}

Data were fed to the computer and analyzed using IBM SPSS Corp. Released 2013. IBM SPSS Statistics for Windows, Version 22.0. Armonk, NY: IBM Corp. Qualitative data were described using number and percent. Quantitative data were described using median (minimum and maximum) for non-parametric data and mean, standard deviation for parametric data after testing normality using Kolmogrov-Smirnov test. Significance of the obtained results was judged at the (0.05) level.

\section{Data analysis:}

Qualitative data: Chi-Square test for comparison of 2 or more groups, Fischer Exact test was used as correction for Chi-Square test when more than $25 \%$ of cells have count less than 5 in $2 * 2$ tables.

Quantitative data between groups: The parametric data were expressed as mean $\pm \mathrm{SD}$ and was analyzed utilizing student $t$-test. VAS score was analyzed among the studied groups utilizing the Mann-Whitney test. Categorical data were presented as patients' number or frequencies (\%) and were analyzed utilizing the Chi-square test or Fisher's exact test when appropriate. $p$-value $<0.05$ was considered significant.

\section{Results}

This double blinded prospective randomized study was done on 50 ASA 1, ASA 2 female patients between age of 20 and 60 years, underwent elective breast surgery (modified radical mastectomy) and referred to pain clinic with postmastectomy pain. Patients characteristics were comparable in both study groups and there was no significant difference in patient characteristics and ASA classification as presented in (Table 1).

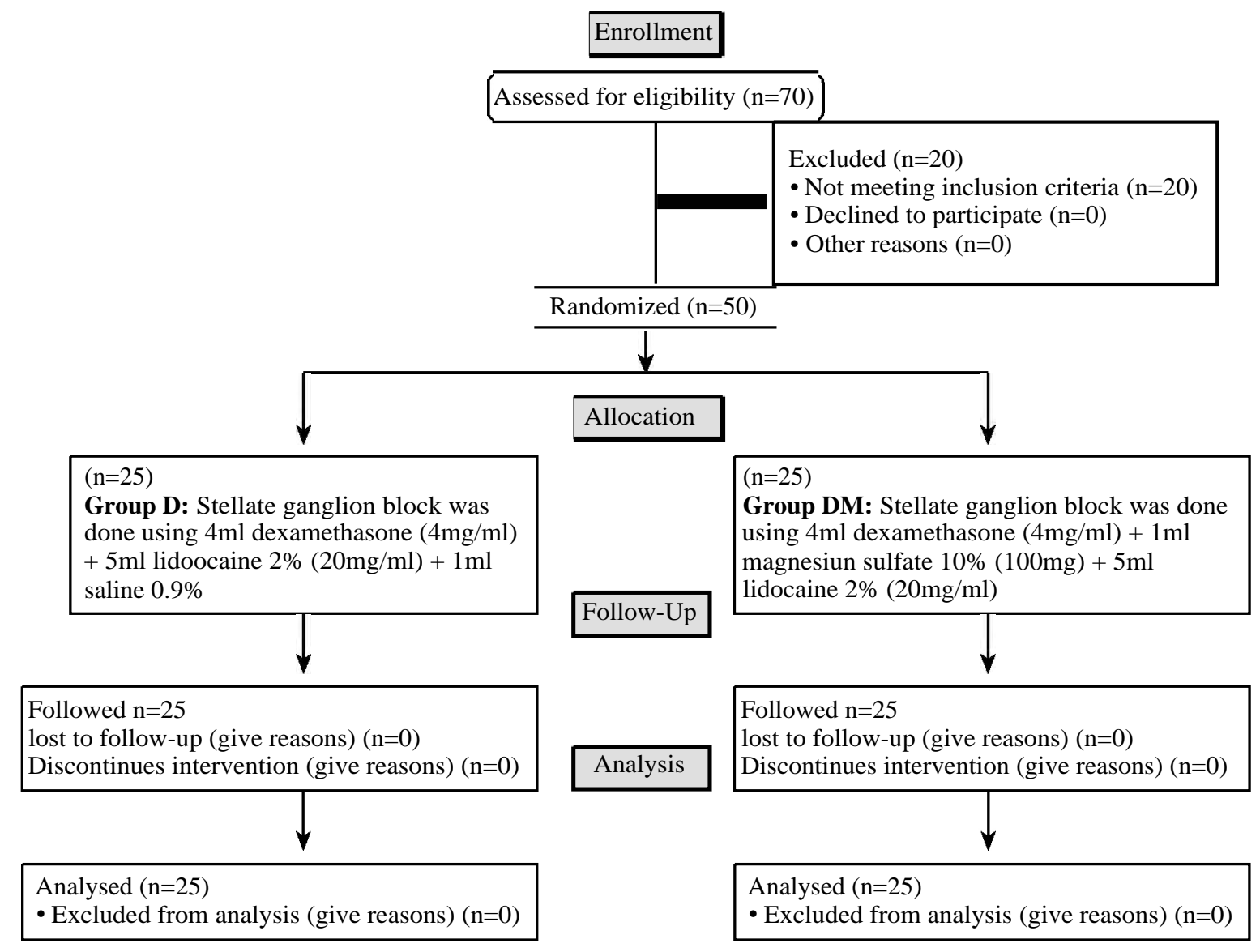

Fig. (2): Consort flow chart showing study design. 
Table (1): Patient's characteristics of the studied groups (data expressed as mean \pm SD or number $\%$ ).

\begin{tabular}{|c|c|c|c|}
\hline & $\begin{array}{c}\text { Group D } \\
\mathrm{N}=25\end{array}$ & $\begin{array}{c}\text { Group DM } \\
\mathrm{N}=25\end{array}$ & $\begin{array}{c}\text { Test of } \\
\text { significance }\end{array}$ \\
\hline Age/years & $46.92 \pm 9.18$ & $45.20 \pm 9.27$ & $p=0.51$ \\
\hline BMI $\left(\mathrm{Kg} / \mathrm{m}^{2}\right)$ & $29.71 \pm 2.39$ & $31.01 \pm 2.58$ & $p=0.07$ \\
\hline $\begin{array}{r}\text { ASA: } \\
1 \\
2\end{array}$ & $\begin{array}{l}16(64.0 \%) \\
9 \quad(36.0 \%)\end{array}$ & $\begin{array}{l}19(76.0 \%) \\
6 \quad(24.0 \%)\end{array}$ & $p=0.35$ \\
\hline $\begin{array}{ll}\text { Group D } & : \text { L } \\
\text { Group DM } & : \mathrm{M} \\
\mathrm{N} & : \mathrm{N} \\
p & : \mathrm{PI}\end{array}$ & $\begin{array}{l}\text { ine and dex } \\
\text { sium sulfate, } \\
\text { er } \\
\text { ility value. }\end{array}$ & $\begin{array}{l}\text { asone group. } \\
\text { aine, and dexa }\end{array}$ & lasone group. \\
\hline
\end{tabular}

VAS was lower in the two study groups after the block through the study period compared to basal values and was significantly lower in group $\mathrm{DM}$ than group $\mathrm{D}$ after 1 month as $p$-value $=0.005$ as in (Table 2) and Fig. (3).

Table (2): VAS score distribution among studied groups (data expressed as median (range)).

\begin{tabular}{lccl}
\hline & $\begin{array}{c}\text { Group D } \\
\mathrm{N}=25\end{array}$ & $\begin{array}{c}\text { Group DM } \\
\mathrm{N}=25\end{array}$ & $\begin{array}{c}\text { Test of } \\
\text { significance }\end{array}$ \\
\hline 5 minutes before injection & $8(6-9)$ & $8(6-9)$ & $p=0.59$ \\
5 minutes after injection & $2(2-3)$ & $2(2-3)$ & $p=0.73$ \\
After 2 weeks & $2(1-5)$ & $2(0-5)$ & $p=0.73$ \\
After 1 month & $4(1-5)$ & $2(0-5)$ & $p=0.005^{*}$ \\
After 2 months & $3(2-4)$ & $3(1-4)$ & $p=0.204$ \\
After 3 months & $3(2-4)$ & $2(1-4)$ & $p=0.078$ \\
\hline
\end{tabular}

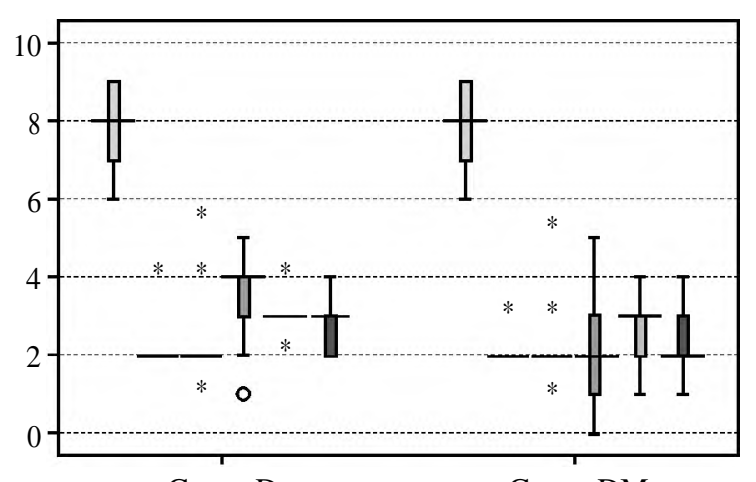

Group D

Group DM

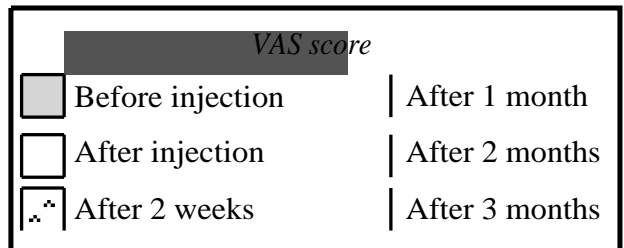

Fig. (3): Median (range) VAS score distribution among studied groups.

The different movements of shoulder (flexion, extension, abduction, internal and external rotation) increased significantly after SGB compared to preblock in the two groups as in (Table 3) and Figs. (4-8).
Table (3): Shoulder mobility mean degree before and after injection among studied groups (data expressed as mean $\pm \mathrm{SD}$ )

\begin{tabular}{|c|c|c|c|}
\hline & $\begin{array}{c}\text { Group D } \\
\mathrm{N}=25\end{array}$ & $\begin{array}{c}\text { Group DM } \\
\mathrm{N}=25\end{array}$ & $\begin{array}{c}\text { Test of } \\
\text { significance }\end{array}$ \\
\hline $\begin{array}{l}\text { Flexion: } \\
\text { 5min before injection } \\
5 \text { min after injection } \\
\text { Paired } t \text {-test }\end{array}$ & $\begin{array}{l}100.52 \pm 13.91 \\
135.28 \pm 15.69 \\
p 2<0.001^{*}\end{array}$ & $\begin{array}{l}100.48 \pm 14.82 \\
138.40 \pm 15.26 \\
p 2<0.001 *\end{array}$ & $\begin{array}{l}p 1=0.99 \\
p 1=0.47\end{array}$ \\
\hline $\begin{array}{l}\text { Extension: } \\
\text { 5min before injection } \\
5 \mathrm{~min} \text { after injection } \\
\text { Paired } t \text {-test }\end{array}$ & $\begin{array}{c}45.92 \pm 7.11 \\
61.92 \pm 5.51 \\
p 2<0.001 *\end{array}$ & $\begin{array}{l}46.0 \pm 6.58 \\
63.16 \pm 5.10 \\
p 2<0.001^{*}\end{array}$ & $\begin{array}{l}p 1=0.96 \\
p 1=0.41\end{array}$ \\
\hline $\begin{array}{l}\text { Abduction: } \\
\text { 5min before injection } \\
5 \text { min after injection } \\
\text { Paired } t \text {-test }\end{array}$ & $\begin{array}{l}100.12 \pm 15.08 \\
132.24 \pm 12.62 \\
p 2<0.001^{*}\end{array}$ & $\begin{array}{l}100.80 \pm 16.34 \\
136.0 \pm 10.02 \\
p 2<0.001 *\end{array}$ & $\begin{array}{l}p 1=0.87 \\
p 1=0.24\end{array}$ \\
\hline $\begin{array}{l}\text { Internal rotation: } \\
5 \text { min before injection } \\
5 \text { min after injection } \\
\text { Paired } t \text {-test }\end{array}$ & $\begin{array}{c}56.96 \pm 9.99 \\
80.20 \pm 8.87 \\
p 2<0.001^{*}\end{array}$ & $\begin{array}{l}55.88 \pm 13.89 \\
82.64 \pm 12.28 \\
p 2<0.001 *\end{array}$ & $\begin{array}{l}p 1=0.75 \\
p 1=0.42\end{array}$ \\
\hline $\begin{array}{l}\text { External rotation: } \\
5 \mathrm{~min} \text { before injection } \\
5 \mathrm{~min} \text { after injection } \\
\text { Paired } t \text {-test }\end{array}$ & $\begin{array}{l}62.60 \pm 8.13 \\
83.72 \pm 6.37 \\
p 2<0.001^{*}\end{array}$ & $\begin{array}{l}60.36 \pm 9.29 \\
85.40 \pm 6.89 \\
p 2<0.001 *\end{array}$ & $\begin{array}{l}p 1=0.36 \\
p 1=0.37\end{array}$ \\
\hline
\end{tabular}

All parameters described as mean $\pm \mathrm{SD}$

$p 1$ (unpaired $t$-test), $p 2$ (paired $t$-test)

* Statistically significant (if $p<0.05$ ).

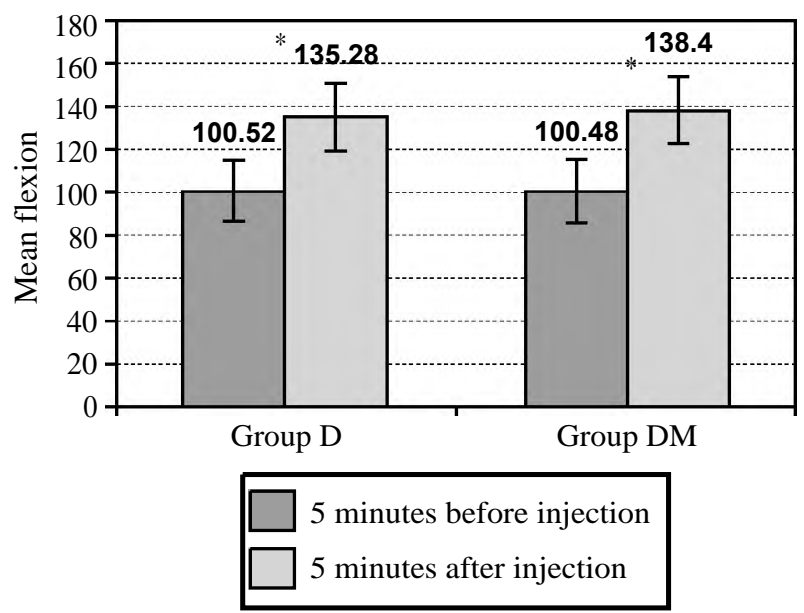

Fig. (4): Mean shoulder mobility in flexion position among studied groups.

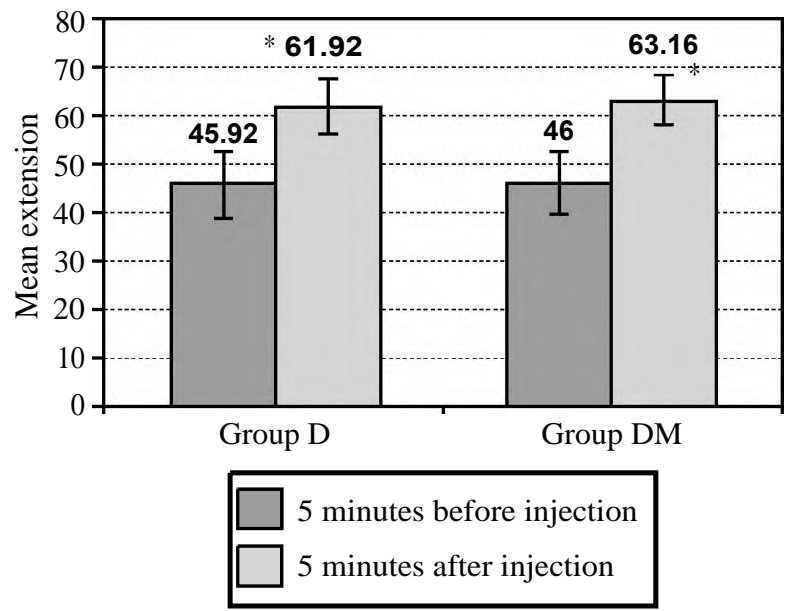

Fig. (5): Mean shoulder mobility in extension position among studied groups. 


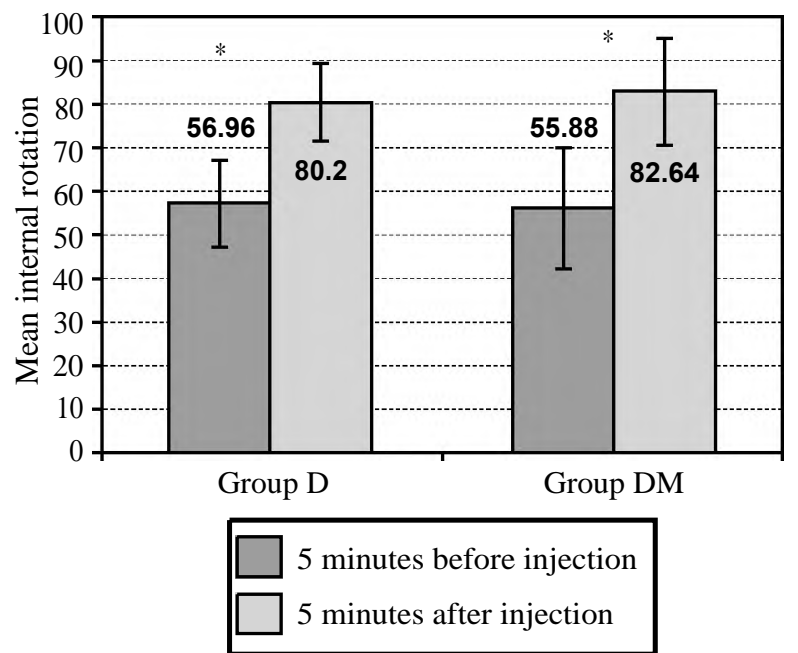

Fig. (6): Mean shoulder mobility in internal rotation position among studied groups.

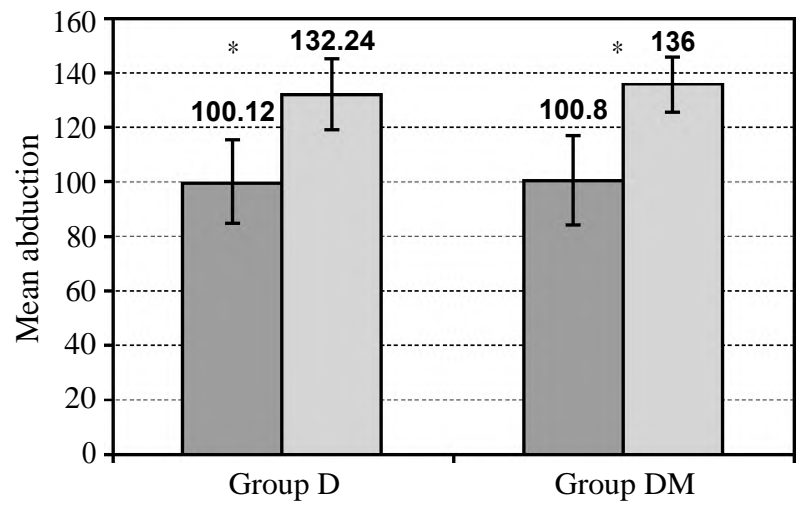

5 minutes before injection

5 minutes after injection

Fig. (7): Mean shoulder mobility in abduction position among studied groups.

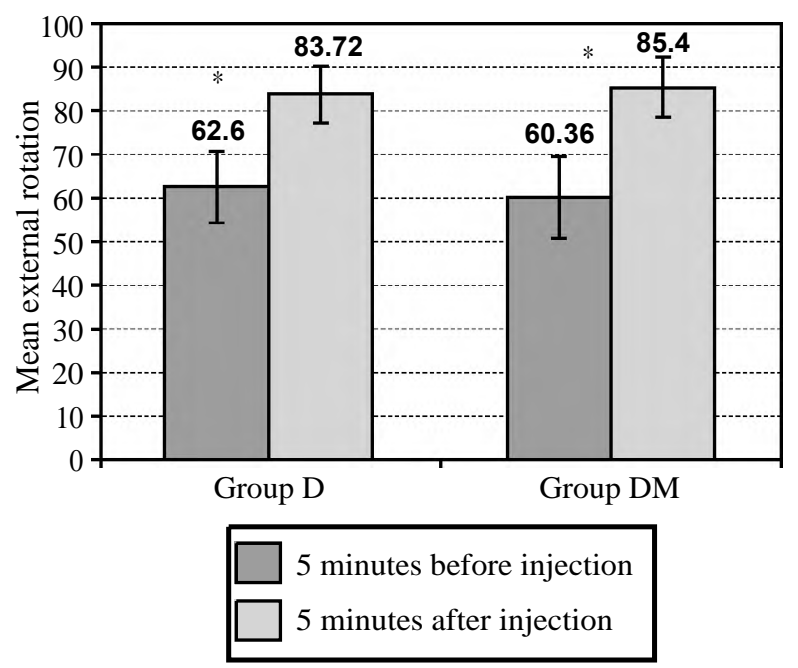

Fig. (8): Mean shoulder mobility in external rotation position among studied groups.
The time to first request to analgesia was significantly longer in group DM than group $\mathrm{D}$ as $p$ value $=0.0016$ as in (Table 4). The total amount of analgesia (gabapentin) taken was statistically significant lower in group DM than group D as $p$ value $=0.006$ as in (Table 4 ) and Figs. (9-11).

Table (4): Analgesic needed data and number of needed injections among studied groups (data expressed as mean $\pm \mathrm{SD}$ or number $\%$ ).

\begin{tabular}{|c|c|c|c|}
\hline & $\begin{array}{c}\text { Group D } \\
\mathrm{N}=25\end{array}$ & $\begin{array}{c}\text { Group DM } \\
\mathrm{N}=25\end{array}$ & $\begin{array}{c}\text { Test of } \\
\text { significance }\end{array}$ \\
\hline $\begin{array}{l}\text { - Time to first request } \\
\text { of analgesia/days }\end{array}$ & $31.24 \pm 14.84$ & $45.08 \pm 23.95$ & $p=0.016^{*}$ \\
\hline $\begin{array}{l}\text { - Total amount of } \\
\text { analgesia } \\
\text { (gabapentin)/mg }\end{array}$ & $10176 \pm 4008.04$ & $7128 \pm 4943.38$ & $p=0.006^{*}$ \\
\hline $\begin{array}{l}\text { - Number of } \\
\text { injections needed: }\end{array}$ & & & \\
\hline 1 & $4 \quad(16.0 \%)$ & $9 \quad(36.0 \%)$ & $p=0.16$ \\
\hline 2 & $11(44.0 \%)$ & $11(44.0 \%)$ & \\
\hline 3 & $10(40.0 \%)$ & $5 \quad(20.0 \%)$ & \\
\hline
\end{tabular}

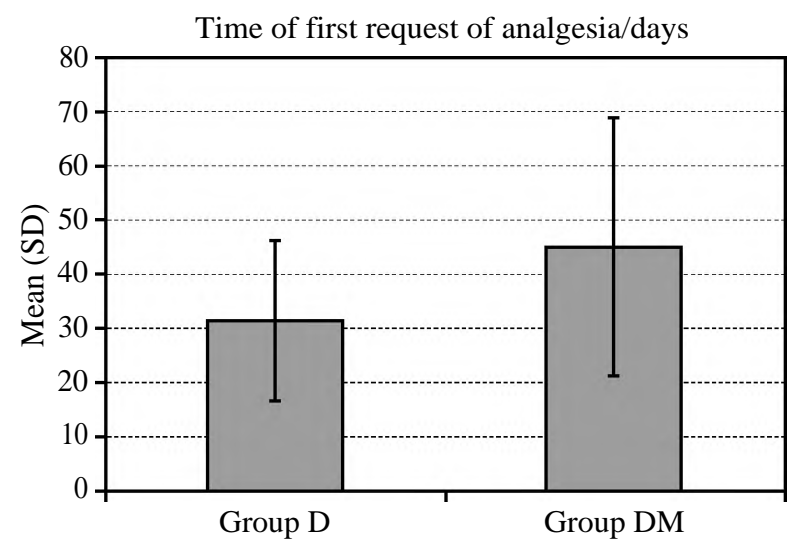

Fig. (9): Bar chart showing mean time to first request of analgesia/days among studied groups.

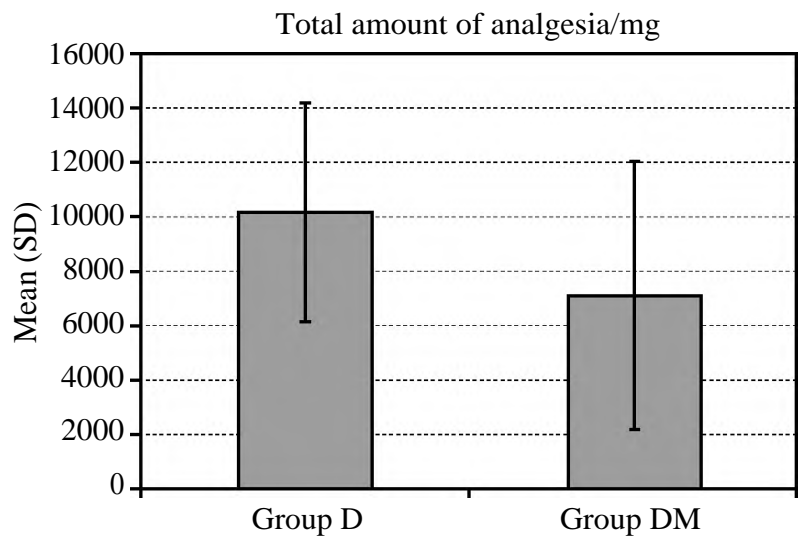

Fig. (10): Bar chart showing mean total amount of analgesia (gabapentin)/mg among studied groups. 


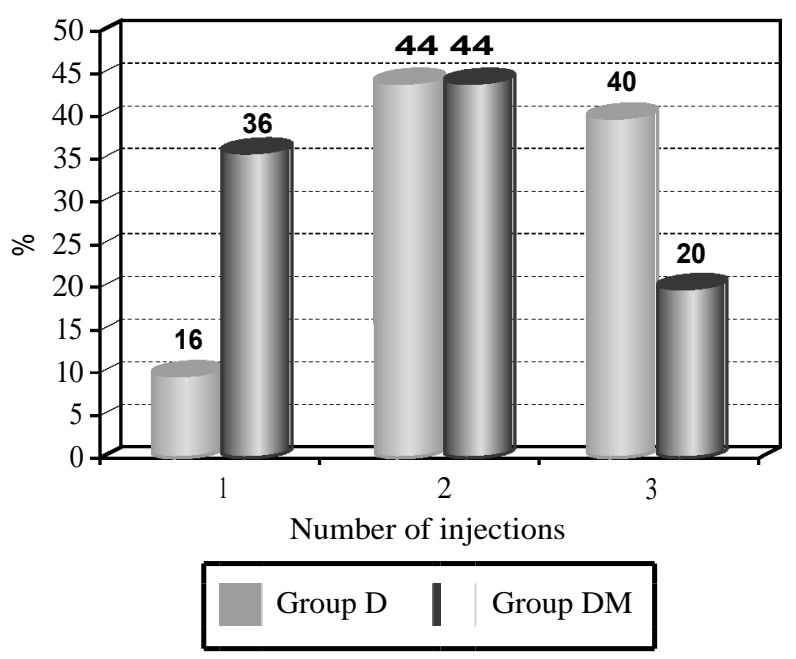

Fig. (11): Number of injections needed among studied groups.

Horner syndrome in the form ptosis, miosis, anhidrosis, enophthalmos and nasal congestion were observed after blocks within 5-15 minutes after blocks in both groups. The skin temperature of ipsilateral arm to the block was elevated by 1 to $3^{\circ} \mathrm{C}$ above the basal value in both study groups. Hypotension occurred in 10 patients in DM group and 11 patients in $\mathrm{D}$ group after injection and was treated by giving $5 \mathrm{mg}$ ephedrine. There were no recorded cases of hematoma, pneumothorax or hypoxia after injection in both study groups. Three patients in magnesium, dexamethasone and lidocaine (DM) group developed hoarseness of voice while four patients in dexamethasone and lidocaine (D) group developed also hoarseness. No respiratory insufficiency or convulsions or weakness in the limb were observed in the study groups.

\section{Discussion}

Persistent pain following mastectomy has been described as early as 1978 . However, pain can develop after any type of breast surgery and not only mastectomy. Chronic pain of this nature can be disabling and a source of considerable distress. The incidence of PBSPS is described to be anywhere between $20 \%$ and $60 \%$ [13]. The resulting debilitating pain persists for years with reported incidence as high as $40 \%$ in 3 years post breast surgery. This is partially due to the poor understanding of the syndrome but also the lack of appropriate treatment [14].

Kojima et al., [15] performed a survey among medical providers in Japan regarding identification and treatment of this syndrome. The authors yielded a $34.7 \%$ response rate and found that $70.5 \%$ rec- ognized PBSPS but only $47.7 \%$ treated it. The majority prescribed NSAIDs to treat PBSPS, therefore the treatment was ineffective, so focusing on the importance of physician education in managing PBSPS is a must. It is important to remember that PBSPS is a chronic pain syndrome and as such, it is a multifactorial condition, linked to anatomical, behavioral and socioeconomic factors [16].

To the best of our knowledge, there were fewer researches that discussed stellate ganglion blockade in PMPS [17]. However, it is broadly considered to be an efficient therapeutic approach for a lot of diseases which include complex regional pain syndrome, pain in the face or head [18]

There was no prior recorded study about effect of magnesium sulphate (MgSO4) as an adjuvant in stellate ganglion block for chronic pain management.

This double blind prospective randomized study was designed to assess using magnesium sulfate as an adjuvant to lidocaine and dexamethasone in ultrasound guided stellate ganglion block for cases of post mastectomy pain syndrome. The primary outcome was the time to first request of analgesia while the secondary outcome was the total amount of recue analgesia needed and pain intensity on VAS.

This study showed that there was significant prolongation of the analgesic duration and time of the first request of analgesia after the block in cases of PMPS in group (DM) more than group (D) when using magnesium sulfate as an adjuvant to lidocaine and dexamethasone for US guided SGB.

Magnesium sulphate is an effective analgesic adjuvant for postoperative pain [19]. Its analgesic property seems to be associated with the regulation of calcium influx into the cells, or antagonism of $\mathrm{N}$-Methyl-D-Aspartate (NMDA) receptors in the central nervous system [20,21]. Additionally, magnesium is known to have an anti-inflammatory effect. Inflammatory state may accompany with pain via peripheral or central sensitization [22] .

Another mechanism for analgesic effect of magnesium is the systemic absorption; serum magnesium levels decreases the post-synaptic activity of slow conducting un-myelinated $\mathrm{C}$-fibers which are the main afferent fibers transmitting pain signals from the periphery to central nervous system [23,24]

In agreement with our results, Gunduz; et al., 2006 [25] concluded that adding 200mg magnesium 
sulfate to prilocaine significantly increase the duration of sensory blocks and time of first request of analgesia when used in the axillary plexus block without systemic side effects or neurotoxicity.

In this study, VAS score was lower in the two study groups compared to basal and lower in magnesium group than the other group. This is in agreement with Farzanegan, et al., 2018 [26] who concluded that co-administration of epidural magnesium with morphine and bupivacaine for postoperative epidural analgesia could decrease VAS score and the amount of opioid consumption without causing adverse outcomes.

In agreement with our results, Ashraf, et al., 2019 [27] concluded that the addition of $100 \mathrm{mg}$ $\mathrm{MgSO} 4$ as an adjuvant to Bupivacaine HCL $0.5 \%$ in patients undergoing elective forearm and hand surgeries under ultrasound guided supraclavicular brachial plexus block anesthesia extended the motor and sensory block durations and provided more efficient post-operative analgesia. In addition, $\mathrm{MgSO} 4$ improved the quality of post-operative recovery which is evinced by the improvement in the sleep quality on the first post-operative night and patient's satisfaction.

Lee, et al., 2012 [28] assessed the effect of the addition of magnesium to bupivacaine-epinephrine mixture in interscalene brachial plexsus block and concluded that the use of magnesium as an additive improved the post-operative pain score and the duration of the post-operative analgesia without significant effect on the onset or the duration of sensory or motor blockade.

Abd-El Salam, et al., 2017 [29] found that addition of $200 \mathrm{mg}$ of magnesium sulfate to bupivacaine in an ultrasound-guided TAP block significantly reduced post-operative opioid requirements, prolonged the duration of analgesia, and decreased the VAS score in patients who underwent abdominal hysterectomy, without significant side effects.

Collins, et al., 2020 [30] evaluated the effect of using intravenous magnesium sulfate for Complex Regional Pain Syndrome type 1 (CRPS) 1 and found that it significantly improved pain, impairment, and quality of life and was well tolerated.

Brill, et al., 2002 [31] studied the efficacy of administration of intravenous $\mathrm{MgSO}_{4}$ in cases of neuropathic pain as post herpetic neuralgia and found that VAS scores were significantly lower for magnesium group compared with placebo group after 20 and 30 minutes of infusion without record- ed adverse effects of magnesium use, so he concluded that physiological action of Mg on NMDA receptors can be translated into a viable concept for pain control in patients with PHN.

Also, Bondok and Abd El-Hady 2006 studied the effect of intra-articular MgSO 4 in knee arthroscopy, and found out that $\mathrm{Mg}$ group showed a significant decrease in the post-operative VAS in the first $24 \mathrm{~h}$ which become less significant thereafter, also, significant decrease in the dosage of postoperative rescue analgesia with a longer time to first analgesic request, concluding that intraarticular $\mathrm{MgSO} 4$ could be a useful substitution for post-operative analgesia.

In another study conducted by Rana; et al., 2016 [32] a bilateral TAP block was performed on patients undergoing abdominal hysterectomy under intrathecal anesthesia, with $18 \mathrm{ml}$ bupivacaine $0.25 \%$ alone or in combination with $150 \mathrm{mg}$ magnesium sulfate. Reduced pain score and rescue analgesic consumption as well as increased duration of analgesia were the outcome after adding magnesium.

In addition, Kaur; et al., 2020 [33] concluded that the addition of $150 \mathrm{mg}$ of magnesium sulfate as an adjuvant to $0.25 \%$ ropivacaine in comparison to $0.25 \%$ ropivacaine alone in PEC block, prolongs the duration of analgesia, significantly decreases the amount of analgesic requirement in first 24 hours post-operatively with persistently lower VAS scores and also lesser number of rescue analgesics. This can contribute significantly to better patient comfort and safety.

Yucel, et al., 2009 [34] also concluded that SGB had successfully decreased VAS and also increased the ROM of the wrist joint in patients with complex regional pain syndrome type 1 .

In our study, the various types of shoulder movements (flexion, extension, abduction, internal, and external rotation) were improved following injection of SGB in both groups compared to basal. The improvement of movement was with no statistically significant difference among both studied groups and that could be explained by the fact that the ROM of shoulder isn't dependent only on pain relief but also on physical therapy. This came in agreement with Jewell, et al. 2009 [35] who displayed that physical therapy, specific exercise and mobilization techniques tend to produce fast result, great improvement, and prevent further tightening of the shoulder. 
In current study, ten patients in DM group and eleven patients in group D developed hypotension after the block and were given 5mg ephedrine. This is in agreement with Fee, et al., 1979 [36] who performed right stellate ganglion block on 24 patients in whom hypertension developed after cardiopulmonary bypass and found that it was associated with a reduction in systolic blood pressure, diastolic blood pressure, and systemic vascular resistance in the majority of cases.

In the present study, the skin temperature of the ipsilateral arm to the block was elevated by 1 to 3 degree Celsius above the baseline following injection and this confirms the success of the block because the increase in the blood flow occurs as result of sympathetic effect of SGB as explained by Yamazaki, et al., 2012 [37] who used laser Doppler blood flowmetry to confirm changes in blood flow following SGB.

In this study, we found that the usage of ultrasound guided technique in SGB reduced complications such as hematoma, pneumothorax and hypoxia as they were not observed in patients after the block. This came in accordance with Rastogi et al., 2010 [38] and Yoo et al., 2012 [39] who demonstrated that ultrasound guided nerve block has changed the practice of regional anesthesia and ultrasound guided SGB provide higher accuracy and more patient safety.

In current study, three cases in DM group and four patients in $\mathrm{D}$ group developed hoarseness of voice. Hoarseness of voice develops owing to spread of local anesthetic to the Recurrent Laryngeal Nerve (RLN). However, Hardy and Wells [40] reported an incidence of $10 \%$ of hoarseness of voice with $10 \mathrm{ml}$ of local anesthetic solution and up to $80 \%$ with $20 \mathrm{ml}$ solution in classical approach.

\section{Conclusion:}

Current study proved that adding of $100 \mathrm{mg}$ of magnesium sulfate to lidocaine and dexamethasone for ultrasound guided stellate ganglion block in cases of post mastectomy pain syndrome increases the time to first request of analgesia, decreases VAS values and the total amount of analgesia (gabapentin dose) needed in three months after the block compared to using lidocaine and dexamethasone alone. Furthermore, magnesium sulfate provides better quality of the block.

\section{References}

1- ZOCCA J.A., CHEN G.H., PUTTANNIAH V.G., HUNG J.C. and GULATI A.: Ultrasound-guided serratus plane block for treatment of postmastectomy pain syndromes in breast cancer patients: A case series. Pain Practice, 17 (1): 141-6, 2017.
2- KHAN J.S., LADHA K.S., ABDALLAH F. and CLARKE H.: Treating Persistent Pain After Breast Cancer Surgery. Drugs, 80 (1): 23-31, 2020.

3- ANDERSEN K.G. and KEHLET H.: Persistent pain after breast cancer treatment: A critical review of risk factors and strategies for prevention. J. Pain, 12 (7): 725-46, 2011.

4- STEVENS P.E., DIBBLE S.L. and MIASKOWSKI C.: Prevalence, characteristics, and impact of postmastectomy pain syndrome: An investigation of women's experiences. Pain, 61 (1): 61-8, 1995.

5- WALDMAN S.D.: Atlas of Interventional Pain Management E-Book: Elsevier Health Sciences; 2014.

6- SCHOLZ A.: Mechanisms of (local) anaesthetics on voltage-gated sodium and other ion channels. Br. J. Anaesth., 89 (1): 52-61, 2002.

7- CALLERY M.P.: Preoperative steroids for laparoscopic surgery. Annals of surgery, 238 (5): 661, 2003.

8- BISGAARD T., KLARSKOV B., KEHLET H. and ROSENBERG J.: Pr-eoperative dexamethasone improves surgical outcome after laparoscopic cholecystectomy: A randomized double-blind placebo-controlled trial. Annals of surgery, 238 (5): 651, 2003.

9- SOAVE P., CONTI G., COSTA R. and ARCANGELI A.: Magnesium and anaesthesia. Current drug targets, 10 (8): 734-43, 2009

10-TURAN A., MEMIS D., KARAMANLIOGLU B., GÜLER T., PAMUKÇU Z.: Intravenous regional anesthesia using lidocaine and magnesium. Anesthesia \& Analgesia, 100 (4): 1189-92, 2005.

11-ABDI S. and YANG Z.: A novel technique for experimental stellate ganglion block in rats. Anesthesia \& Analgesia, 101 (2): 561-5, 2005.

12- SEELAM S., NAIR A.S., CHRISTOPHER A., UPPUTURI O., NAIK V. and RAYANI B.K.: Efficacy of single-shot ultrasound-guided erector spinae plane block for postoperative analgesia after mastectomy: A randomized controlled study. Saudi J. Anaesth., 14 (1): 22, 2020.

13- De MENEZES COUCEIRO T.C., De MENEZES T.C. and VALÊNÇA M.M.: Post-mastectomy pain syndrome. The magnitude of the problem. "Braz. J. Anesthesiol., 59 (3): 358-65, 2009.

14- MACDONALD L., BRUCE J., SCOTT N.W., SMITH W.C.S. and CHAMBERS W.: Long-term follow-up of breast cancer survivors with post-mastectomy pain syndrome. Br. J. Cancer, 92 (2): 225-30, 2005.

15- KOJIMA K.Y., KITAHARA M., MATOBA M., SHIMOYAMA N. and UEZONO S.: Survey on recognition of post-mastectomy pain syndrome by breast specialist physician and present status of treatment in Japan, 21 (2): 191-7, 2014.

16- CAFFO O., AMICHETTI M., FERRO A., LUCENTI A., VALDUGA F. and GALLIGIONI E.: Pain and quality of life after surgery for breast cancer. Breast Cancer Res. Treat., 80 (1): 39-48, 2003.

17- JADON A.: Revalidation of a modified and safe approach of stellate ganglion block. Indian J. Anaesth., 55 (1): 52, 2011. 
18- MOON H.S., CHON J.Y., LEE S.H., JU Y.M. and SUNG C.H.: Long-term results of stellate ganglion block in patients with olfactory dysfunction. Korean J. Pain, 26 (1): 57, 2013.

19- ALBRECHT E., KIRKHAM K., LIU S. and BRULL R.: The analgesic efficacy and safety of neuraxial magnesium sulphate: A quantitative review. Anaesthesia, 68 (2): 190202, 2013.

20- FERIA M., ABAD F., SÁNCHEZ A. and ABREU P.: Magnesium sulphate injected subcutaneously suppresses autotomy in peripherally deafferented rats. Pain, 53 (3): 287-93, 1993.

21- WOOLF C.J. and THOMPSON S.W.: The induction and maintenance of central sensitization is dependent on $\mathrm{N}$ methyl-D-aspartic acid receptor activation; implications for the treatment of post-injury pain hypersensitivity states. Pain, 44 (3): 293-9, 1991.

22- SHIN H.J., KIM E.Y., NA H.S., KIM T., KIM M.H. and DO S.H.: Magnesium sulphate attenuates acute postoperative pain and increased pain intensity after surgical injury in staged bilateral total knee arthroplasty: A randomized, double-blinded, placebo-controlled trial. Br. J. Anaesth., 117 (4): 497-503, 2016.

23- HERROEDER S., SCHÖNHERR M.E., De HERT S.G., HOLLMANN M.W. and WARNER D.S.: Magnesiumessentials for anesthesiologists. Anesthesiology, 114 (4): 971-93, 2011.

24- BUVANENDRAN A. and KROIN J.S.: Useful adjuvants for post-operative pain management. Best practice \& research Clinical anaesthesiology, 21 (1): 31-49, 2007.

25- GUNDUZ A., BILIR A. and GULEC S.: Magnesium added to prilocaine prolongs the duration of axillary plexus block. Regional Anesthesia \& Pain Medicine, 31 (3): 233-6, 2006.

26- FARZANEGAN B., ZANGI M., SAEEDI K., KHALILI A., RAJABI M., JAHANGIRIFARD A., EMAMI H., MAHBOOBIPOUR A.A. and BANIASADI S.: Effect of Adding Magnesium Sulphate to Epidural Bupivacaine and Morphine on Post-Thoracotomy Pain Management: A Randomized, Double-Blind, Clinical Trial. Basic \& clinical pharmacology \& toxicology, 123 (5): 602-6, 2018.

27- GHALI A.M., MOLOKHIA K.M.A. and AHMED S.A.: The Effect on Outcome of Adding Magnesium Sulphate to Bupivacaine in the Ultrasound-guided Supraclavicular Brachial Plexus Block Anesthesia. Journal of Clinical Anesthesia, 7 (1): 13, 2019.

28- LEE A.R., YI H.W., CHUNG I.S., KO J.S., AHN H.J., GWAK M.S., CHOI D.H. and CHOI S.J.: Magnesium added to bupivacaine prolongs the duration of analgesia after interscalene nerve block. Can. J. Anaesth., 59 (1): 21-7, 2012.
29- ABD EL-RAHMAN A.M.: Efficacy of magnesium sulfate added to local anesthetic in a transversus abdominis plane block for analgesia following total abdominal hysterectomy: A randomized trial. Pain physician, 20: 641-7, 2017.

30- COLLINS S., ZUURMOND W.W., De LANGE J.J., VAN HILTEN N.J. and PEREZ R.S.: Intravenous magnesium for complex regional pain syndrome type 1 patients: A pilot study. Pain Med., 70: 194-7. Endod. J., 2009.

31- BRILL S., SEDGWICK P., HAMANN W. and Di VADI P.: Efficacy of intravenous magnesium in neuropathic pain. Br. J. Anaesth., 89 (5): 711-4, 2002.

32- RANA S., VERMA R.K., SINGH J., CHAUDHARY S.K. and CHANDEL A.: Magnesium sulphate as an adjuvant to bupivacaine in ultrasound-guided transversus abdominis plane block in patients scheduled for total abdominal hysterectomy under subarachnoid block. Indian J. Anaesth., 60 (3): 174, 2016.

33- KAUR H., JHAND H.K., BAGHLA N., CHAUDHRY D., SINGH A. and KAUR R.: Analgesic effect of magnesium sulfate as an adjuvant to ropivacaine in pectoral nerve block. Bali J. Anaesthesiol., 4 (4): 156, 2020.

34- YUCEL I., DEMIRARAN Y., OZTURAN K. and DEGIRMENCI E.: Complex regional pain syndrome type I: Efficacy of stellate ganglion blockade. J. Orthop. Trauma., 10 (4): 179-83, 2009.

35- JEWELL D.V., RIDDLE D.L. and THACKER L.R.: Interventions associated with an increased or decreased likelihood of pain reduction and improved function in patients with adhesive capsulitis: A retrospective cohort study. Physical therapy, 89 (5): 419-29, 2009.

36- FEE H.J., VILJOEN J.F., CUKINGNAN R.A. and CANAS M.S.: Right stellate ganglion block for treatment of hypertension after cardiopulmonary bypass. Ann. Thorac. Cardiovasc. Surg., 27 (6): 519-22, 1979.

37- YAMAZAKI H., NISHIYAMA J. and SUZUKI T.: Use of perfusion index from pulse oximetry to determine efficacy of stellate ganglion block. Local and regional anesthesia, 5: 9, 2012.

38- RASTOGI S. and TRIPATHI S.: Cardiac arrest following stellate ganglion block performed under ultrasound guidance. Anaesthesia, 65 (10): 1042-42, 2010.

39- YOO S.D., JUNG S.S., KIM H.S., YUN D.H., KIM D.H., CHON J. and HONG D.W.: Efficacy of ultrasonography guided stellate ganglion blockade in the stroke patients with complex regional pain syndrome. Ann. Rehabil. Med., 36 (5): 633, 2012.

40- HARDY P. and WELLS J.: Extent of sympathetic blockade after stellate ganglion block with bupivacaine. Pain, 36 (2): 193-6, 1989. 


\section{كبريتات الماغنسيوم كعامل مساعد فى إحضار العقدة النجمية

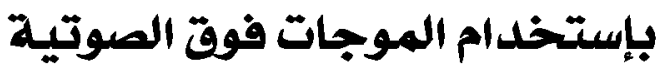

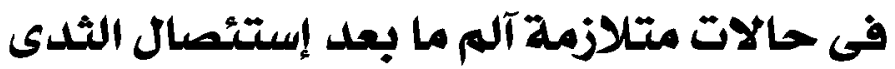

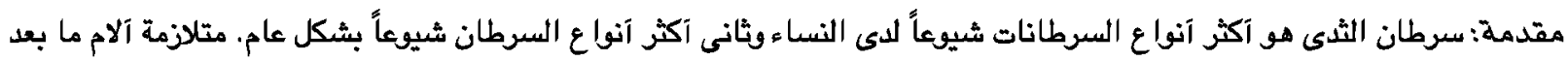

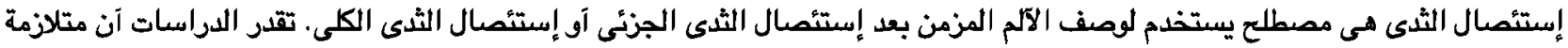

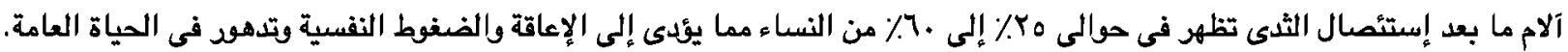
الهدف من العمل: كان الهدف من الدراسة هو مقارنة فعالية المسكنات ومدة تثبيط العقدة النجمية عند إستخدام كل من ديكساميثانين

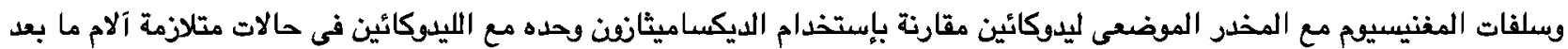
إستئمال الثدى. المفنيع.

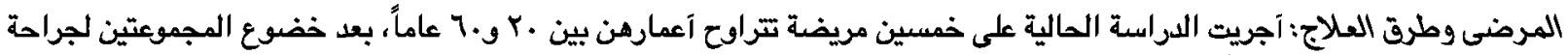

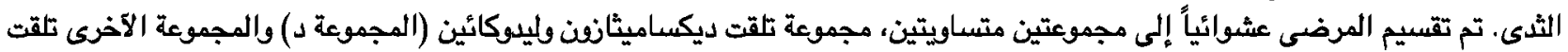

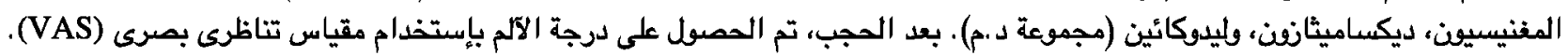

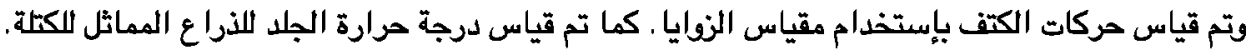

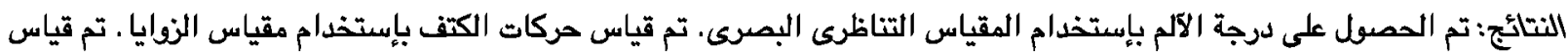

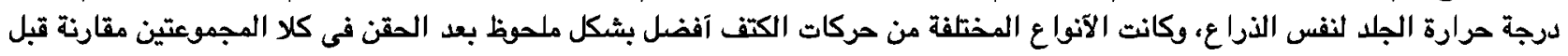

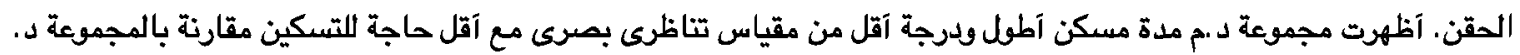

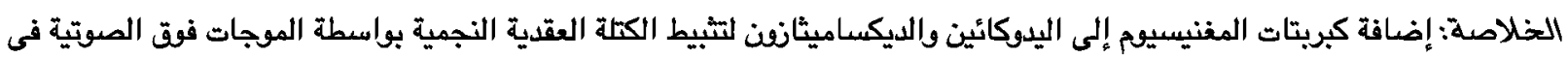

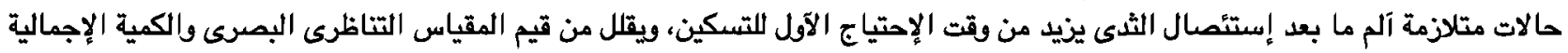
للآدوية المسكثة اللازمة فى المتابعة. 